\title{
CONTEXT, INPUT, PROCESS, PRODUCT ANALYSIS IN THE IMPLEMENTATION OF IRON SUPPLEMENTATION PROGRAM IN BANYUMAS, CENTRAL JAVA
}

\author{
Purwati1), Didik Tamtomo'), Endang Sutisna Sulaeman³) \\ 1)Diploma III Program in Midwifery Muhammadiyah University Purwokerto, \\ Central Java \\ 2)Faculty of Medicine, Sebelas Maret University \\ 3)Masters Program in Public Health, Sebelas Maret University
}

\begin{abstract}
Background: Iron supplementation program has been implemented in Banyumas, District, Central Java, but the prevalence of anemia in pregnant women remains as high as 55.37\%. The Banyumas District Health Office has launched an ad hoc (temporary) iron supplementation program, namely Hemafort, in order to reduce anemia prevalence. This study aimed to investigate the factors that determine the effectiveness of the iron supplementation program for pregnant women in Banyumas, Central Java.

Subjects and Method: This was a qualitative study with case study approach, and CIPP (context, input, process, product) framework. This study was conducted Wangon II and South Purwokerto Health Centers from October to November 2016. Informants were selected by purposive sampling including midwives, nutritional program managers, pharmacists, head of nutrition section, and pregnant women. The data were collected by in-depth interview, observation, and archival review. The data were analyzed by a multiple case study. The data were validated by data source triangulation.

Results: The iron tablets coverage for pregnant women reached $94.88 \%$ and 89.26\% in 2014 and 2015, respectively, in Banyumas. The minimal target of iron coverage for pregnant women was $90 \%$. There was no local government policy or standard operating procedure (SOP) that regulated the efforts to tackle anemia problems in pregnant women. The number of health personnel in charge of nutrition and their competence were sufficient. But reliable budget to tackle anemia problem did not exist. Spending district budget was an exit strategy to take when there was deficiency in central budget allocation. The number of iron supplementation tablets was not guaranteed.

Conclusion: The effectiveness of iron supplementation program for pregnant women depends on the existence of relevant policy, SOP, allocation of sufficient and reliable budget, as well as adequate supply of iron tablets.
\end{abstract}

Keywords: iron supplementation tablets, pregnant women, local government, budget

Correspondence: Purwati. Faculty of Health Sciences, Muhammadiyah University at Purwokerto, Central Java. Email: watix_1006@yahoo.com. Mobile: +6285735145236 . 